Sharif University of Technology
Scientia Iranica
SCIENTIA
I RAN I CA
http://scientiairanica.sharif.edu

\title{
Bridge backwater estimation: A comparison between artificial intelligence models and explicit equations
}

\author{
M. Niazkar*, N. Talebbeydokhti, and S.H. Afzali \\ School of Engineering, Department of Civil and Environmental Engineering, Shiraz University, Zand Blvd., Shiraz, Iran.
}

Received 17 July 2018; received in revised form 19 September 2019; accepted 10 February 2020

\section{KEYWORDS}

Hydraulic structures;

Bridge backwater

estimation;

Genetic programming;

Explicit equation;

Artificial neural

network.

\begin{abstract}
Estimation of bridge backwater has been one of the practical challenges of hydraulic engineering for decades. In this study, Genetic Programming (GP) was employed to estimate bridge backwater for the first time based on the conducted literature review. Furthermore, two new explicit equations were developed to predict bridge afflux using Genetic Algorithm (GA) and hybrid MHBMO-GRG algorithm. The performance of these models was compared with that of the Artificial Neural Network (ANN) and several explicit equations available in the literature considering both laboratory and field data. According to five considered performance evaluation criteria, two new explicit equations outperformed those available in the literature. Furthermore, GP and ANN achieved the best results with respect to four out of five considered criteria for training and testing datasets, respectively. To be more specific, ANN improved the Mean Square Error (MSE) and $R^{2}$ values of the explicit equation developed using GA by $44 \%$ and $12 \%$ for the testing data while GP enhanced the corresponding values by $62 \%$ and $9 \%$ for the training data. Finally, the results indicated that not only the artificial intelligence models considerably improved bridge afflux estimations in comparison to the explicit equations but also the suggested equations could significantly improve the accuracy of the available explicit equations.
\end{abstract}

(C) 2021 Sharif University of Technology. All rights reserved.

\section{Introduction}

Bridges are undoubtedly useful structures across waterways that connect river sides together for transfer purposes. However, they may confine a natural space for water flow in rivers. Particularly, water surface at the upstream of bridges built over rivers may rise more than its normal limit due to the provided confinement during flood event. This increase in water level with

\footnotetext{
*. Corresponding author.

E-mail addresses: mniazkar@shirazu.ac.ir (M. Niazkar); taleb@shirazu.ac.ir (N. Talebbeydokhti); afzali@shirazu.ac.ir (S.H. Afzali)
}

doi: $10.24200 /$ sci. 2020.51432 .2175 respect to normal water depth is invariantly called bridge afflux or backwater.

Since bridge backwater has important impacts on flood defense schemes as well as river planning and management projects, searching for methods that provide better estimation of this phenomenon has been studied over decades. To this end, many attempts have been made which can be classified from different viewpoints. In this respect, in terms of type of bridges, such research attempts can be regarded as contributions focusing on bridges with either horizontal soffit [1] or arch deck [2-4]. From the methodological point of view, some researchers employed numerical $[5,6]$, experimental $[7,8]$, and data mining approaches [3,9-11] to predict bridge backwater. Furthermore, most of these methods estimating bridge afflux have 
been basically developed based on field or laboratory datasets. The numerical models can be classified into different types of methods to predict bridge backwater including: (1) energy method [12-14], (2) momentum method [15], (3) WSPRO [16], (4) Yarnell's method [17], (5) HR method [18], and (6) USBPR method [19]. Although some of these numerical models have been implemented in numerical software for simulating rivers and hydraulic structures, such as ISIS package [20] and HEC-RAS [12-16], such shortcomings as the need for calibration, requirement for quite large data sets, and flexible applicability under certain specified assumptions make these models unable to estimate backwater for different types of bridges.

Since the present study focuses primarily on estimating backwater in arched bridges, the relevant contributions are particularly reviewed in the following. Among the studies conducted for this type of bridge, Biery and Delleur's research [2] is the most well-known one. They conducted backwater analysis of single-span arch bridges and proposed an explicit empirical correlation which attributed bridge afflux to the Froude number and opening ratio. Brown [18] not only conducted numerous experimental studies on different types of bridge constrictions, but also collected a variety of bridge backwater field data from 1946 to 1983 . He finally proposed HR method that could estimate backwater for arch bridges using normal depth, Froude number, and blockage ratio. Later, this method was used as one of bridge subroutine approaches in the ISIS package program [20]. Despite the common applications of explicit equations used for estimating many variables in different applications of water resources [21-25], they should be used only when their background assumption(s) and valid ranges are applicable. In this regard, the limitations of the available explicit equations for predicting backwater depth are that (1) they were not developed by powerful algorithms and (2) were not accurate enough to be applied to professional software to analyze rivers and design hydraulic structures. In order to enhance the accuracy of backwater estimation based on experimental and field databases, Artificial Intelligence (AI) models such as function-based Radial Basis Neural Network (RBNN), Multi-Layer Perceptron (MLP), Generalized Regression Neural Networks (GRNN), and Adaptive Neuro-Fuzzy Inference System (ANFIS) were employed $[3,4,10,11]$. Despite all these studies, an accurate explicit equation, which could take all involved variables into account and be developed by powerful algorithms like Genetic Algorithm (GA), has not been proposed based on the current literature. Although several AI models, such as ANN, were applied to estimate the afflux of arched bridges, Genetic Programming (GP) successfully used for solving other water-related problems $[23,26,27]$ has not been utilized yet. Given that better bridge backwater estimation can yield more sustainable and reliable schemes for bridge safety during flood events, developing new explicit equations with higher accuracy through powerful optimization algorithms and utilizing other powerful data mining approaches are still required.

In this paper, two new explicit equations were developed to estimate bridge afflux using GA and Modified Honey Bee Mating Optimization (MHBMO) and Generalized Reduced Gradient (GRG) Algorithms. These algorithms have been efficiently used for solving different civil and water engineering problems in the literature $[21,22,28-30]$. However, to the authors' knowledge, it is the first time that they have been applied to estimate bridge backwater depth. Moreover, GP has been used for similar purpose for the first time in the literature. The performances of these three models are compared with those of Artificial Neural Network (ANN) and three other explicit equations available in the literature. The obtained results for afflux prediction based on the reliable database showed that these new models could significantly improve the estimation.

\section{Bridge backwater problems}

In order to understand this phenomenon better, a schematic situation of bridge backwater is depicted in Figure 1. As observed, water suitably flows along the river and under the bridge with normal depth. However, a rise in the water surface level would be due to bridge constriction during flood events. In Figure 1, $d h$ is bridge backwater and $D_{1}$ and $D_{3}$ represent normal flow depth in Sections 1 and 3, respectively.

According to the previous studies [3,8-10,31], four parameters have the most significant impacts on bridge backwater including (1) the ratio of blockage area of bridge at depth $D_{1}$ to the flow area in Section 1 upstream of the bridge $\left(J_{1}\right),(2)$ ratio of blockage area of bridge at depth $D_{3}$ to the flow area in Section 3 downstream of the bridge $\left(J_{3}\right),(3)$ Froude number in Section $3\left(F_{3}\right)$, and (4) downstream normal depth $\left(D_{3}\right)$. Based on these parameters, bridge afflux $(d h)$ can be evaluated for arched bridge constructions in rivers. Through dimensionless analysis, the bridge backwater can be determined as follows:

$$
\frac{d h}{D_{3}}=F\left(J_{1}, J_{3}, F_{3}\right)
$$

where $F$ is function. Three empirical formulas for bridge backwater available in the literature include Biery and Delleur [2], Multiple Linear Regressions (MLR) [3], and Multiple Non-Linear Regressions (MNLR) [3]. The corresponding equations are shown in Eqs. (2)-(4). 


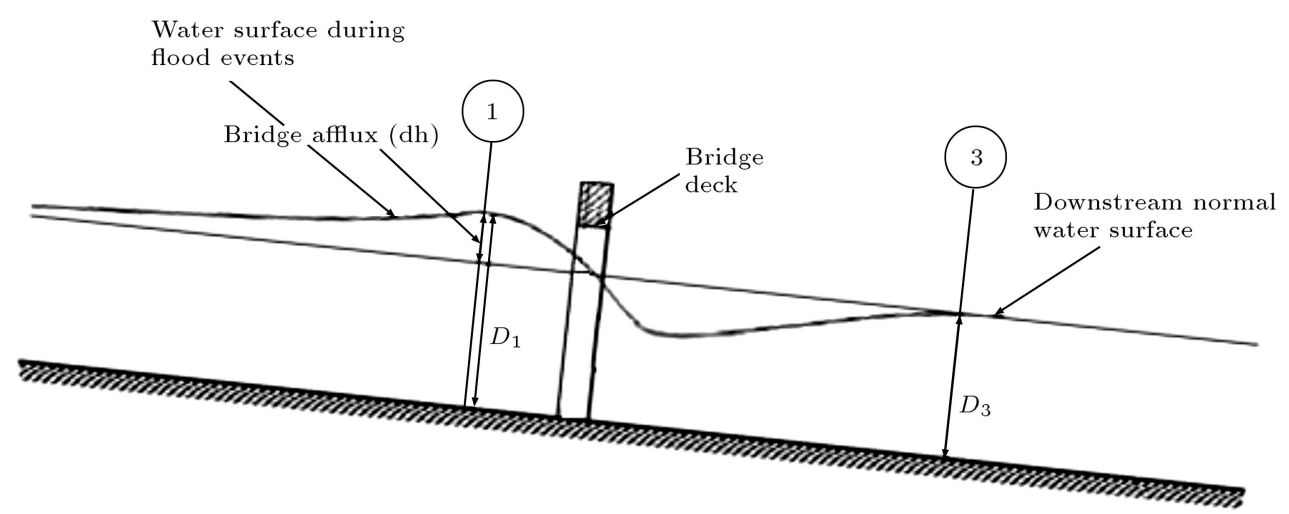

Figure 1. A schematic illustration of bridge backwater caused by bridge constrictions.

$$
\begin{aligned}
\frac{d h}{D_{3}} & =0.47 \times\left(\frac{F_{3}}{1-J_{3}}\right)^{2.26}, \\
\frac{d h}{D_{3}} & =1.62 \times J_{1}-1.54 \times J_{3}+0.429 \times F_{3}, \\
\frac{d h}{D_{3}} & =1.311 \frac{J_{1}^{1.8} F_{3}^{1.23}}{J_{3}^{0.744}} .
\end{aligned}
$$

Among these explicit equations, Biery and Delleur's [2] equation is the most commonly used empirical formula for bridge backwater. As shown in Eq. (2), although the impact of $J_{1}$ is not considered in this equation, it should be considered as a general function shown in Eq. (1). According to Biery and Delleur's [2] formula, bridge backwater increases with an increase in the Froude number in downstream section and decreases with a decrease in $J_{3}$. However, Eqs. (3) and (4) take into account all the independent parameters involved in bridge backwater. The main difference between Eq. (3) and Eq. (4) is that the former is linear, while the latter considers a nonlinear relationship among the involved parameters.

\section{Methods and materials}

In this section, first, the data considered for bridge backwater is introduced. Second, the proposed empirical models are presented. Finally, different methods used for estimating backwater depth in this study are briefly described.

\subsection{Bridge backwater database}

As mentioned earlier, a majority of the available methods for backwater estimation have been developed using laboratory and/or field data. Accordingly, the data considered in this study comprise both experimental and field datasets. The experimental data are originally related to Hydraulic Research Wallingford experiments conducted based on studies on backwater estimation. The field data include 66 field data observed from 1946 and 1983 [18]. Moreover, the 202-
Table 1. Comparison of the four statistical criteria for different models.

\begin{tabular}{ccccc}
\hline Parameters & $\boldsymbol{J}_{\mathbf{1}}$ & $\boldsymbol{J}_{\mathbf{3}}$ & $\boldsymbol{F}_{\mathbf{3}}$ & $\boldsymbol{d} \boldsymbol{h} / \boldsymbol{D}_{\mathbf{3}}$ \\
\hline \multicolumn{5}{c}{ Total data } \\
Maximum & 0.803 & 0.742 & 1.809 & 1.805 \\
Minimum & 0.064 & 0.047 & 0.008 & 0.002 \\
Average & 0.452 & 0.385 & 0.367 & 0.253 \\
\hline Train data \\
Maximum & 0.803 & 0.742 & 1.809 & 1.805 \\
Minimum & 0.064 & 0.047 & 0.008 & 0.002 \\
Average & 0.455 & 0.388 & 0.374 & 0.261 \\
\hline \multicolumn{5}{c}{ Test data } \\
Maximum & 0.746 & 0.678 & 1.021 & 0.685 \\
Minimum & 0.099 & 0.097 & 0.053 & 0.008 \\
Average & 0.440 & 0.374 & 0.340 & 0.223 \\
\hline
\end{tabular}

laboratory data analysis was carried out on two different rectangular flumes incorporating different types of arched bridges. The $J_{1}, J_{3}, F_{3}$, and $d h / D_{3}$ ranges of these data are summarized in Table 1. Moreover, the variations of $d h / D_{3}$ with $J_{1}, J_{3}$, and $F_{3}$ are depicted in Figure 2, according to which most data points in this database have similar values for $J_{1}$ and $J_{3}$ and the amount of $F_{3}$ is lower than 0.75. Moreover, Figure 2 shows that the values of dimensionless bridge backwater depth $\left(d h / D_{3}\right)$ are lower than 0.78 for most data. Since this database has been already utilized in several studies $[3,10,18]$, it is technically reliable for developing equations with improved accuracy to estimate bridge backwater.

\subsection{Proposed models for explicit backwater estimation}

According to the presented literature review, an explicit equation with high precision is still required to estimate backwater in arched bridges. In this regard, after examining many different functions to determine a qualified formula, a new structure for 


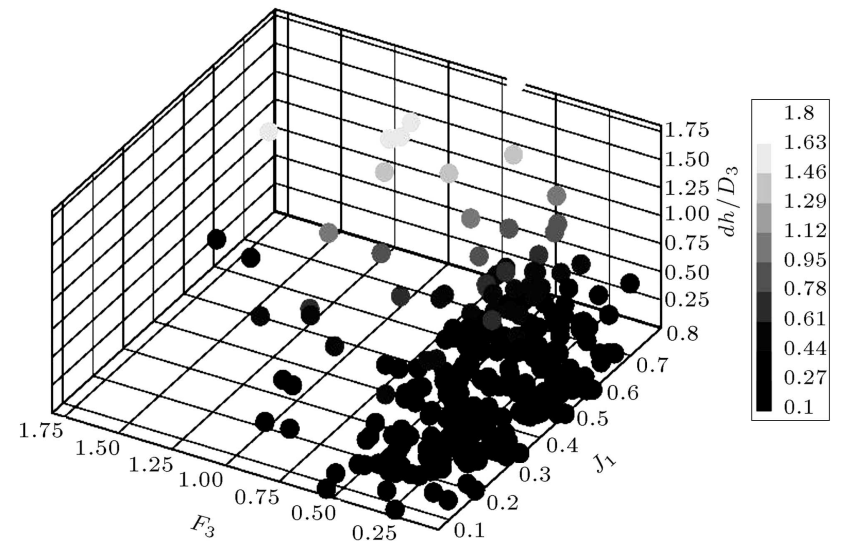

(a)

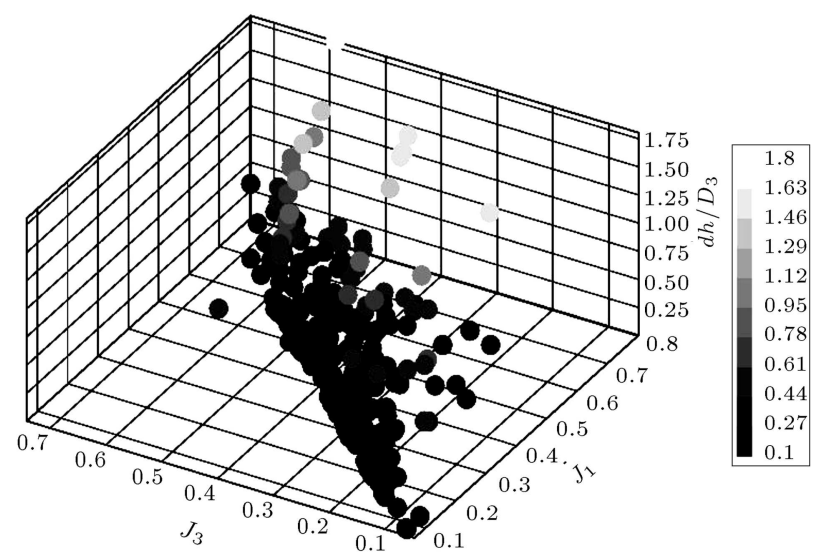

(b)

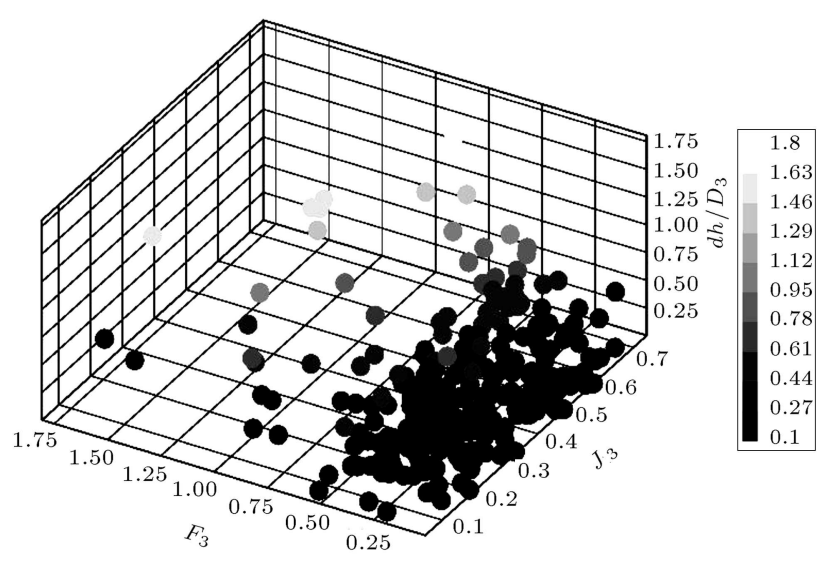

(c)

Figure 2. Variation of $d h / D_{3}$ with respect to (a) $J_{1}$ and $F_{3}$, (b) $J_{1}$ and $J_{3}$, and (c) $J_{3}$ and $F_{3}$.

explicit equation was obtained and proposed for afflux estimation. This simple-structured model is shown in the following:

$$
\frac{d h}{D_{3}}= \begin{cases}p_{1} J_{1}^{p_{2}} J_{3}^{p_{3}} F_{3}^{p_{4}} & \text { for } F_{3}<p_{9} \\ p_{5} J_{1}^{p_{6}} J_{3}^{p_{7}} F_{3}^{p_{8}} & \text { for } F_{3} \geq p_{9}\end{cases}
$$

where $p_{i}$ for $i=1,2, \ldots, 9$ are the unknown coefficients of the new proposed model.

As shown in Eq. (5), the proposed model, requiring nine coefficients to be calibrated, divides the whole dataset into two parts based on the value of the Froude number of the downstream section $\left(F_{3}\right)$. In each part, bridge backwater may be calculated using a simple nonlinear equation obtained by multiplying all the involved parameters. All coefficients of the new proposed model were optimized based on the field and laboratory database. Unlike Biery and Delleur's [2] model (Eq. (2)), the proposed model considers all involved parameters while estimating bridge backwater.

\subsection{Artificial Neural Network (ANN)}

The theory of ANN was presented in a number of references and applied to a variety of problems in different fields, particularly hydraulic and water resources engineering [27,32-34]. A typical ANN includes some elements invariantly called neurons grouped in layers. The neurons in the input layer take a vector that consists of input data. These neurons are responsible for transmitting the values to the next layer through connections. Each neuron in a layer is connected to all other neurons of the next layer while they are all not connected with each other. The data flow through these connections from one neuron to another is multiplied by weights that control the strength of a passing signal. In case the output layer is grasped in feed-forward networks, the data process continues while the data flows exclusively in one direction. However, the Feed Forward Back Propagation (FFBP) uses one or more hidden layers while the neurons in this layer intervene between the external input and the network output to improve the performance of the network.

The data utilized in this study for backwater depth estimation have three input parameters, i.e., $J_{1}, J_{3}$, and $F_{3}$, and one output parameter, $d h / D_{3}$. The considered network has input, output, and hidden layers that consist of three, ten, and one neurons, respectively. The Levenberg Marquardt optimization technique was used to train the FFBP. According to the literature, ANN has already been used for bridge backwater estimation as well as comparison purposes.

\subsection{Genetic Algorithm ( $G A$ )}

GA is a zero-order search-based optimization algorithm that mimics the mechanism of natural selection and evolution. This algorithm is widely used with numerous applications [22]. Three genetic operators such as crossover, mutation, and selection are commonly utilized in GA to create new combinations of variables and find better solutions. Not only does the crossover operator exchange genetic information among selected population members, but also it combines the information of the selected parents to form new strings. This 
combination is made possible probabilistically through a swapping process. The mutation operator allows and maintains the diversity of genetic information by randomly changing the characteristics of the individual population. Finally, the selection operator, as its name indicates, chooses the best solutions.

In this study, a population size equal to 300 in number is adopted. Since the proposed model for bridge backwater has nine unknown coefficients, GA was used to calibrate these nine decision variables.

\subsection{Genetic Programming (GP)}

GP, a random search heuristic method which is quite similar to GA, operates on parse trees, whereas GA considers bit strings. In essence, this technique applies a wide range of variables and functions to a flexible tree-structured base that in evitably makes GP a powerful tool to find the existing relations that best fit the relation between the input and output variables of a system.

The main steps of GP include initialization, selection, reproduction, and termination. First, it considers an initial population, which consists of randomly generated programs (equations). These programs are basically derived from a random combination of input variables, random numbers, and functions. The considered population is subjected to an evolutionary process to find and select individual programs that best describe the relation between the input and output variables. The part of the information between the selected programs is exchanged to create better programs using genetic operators such as crossover and mutation. This evolution process is repeated over consecutive generations until symbolic expressions describing the data are reached. Further details of GP may be found in Koza et al. [35] for interested readers. Discipulus [36] software, used for implementing GP in many studies $[23,26,27]$, was applied in this research.

\subsection{The hybrid MHBMO-GRG algorithm}

The hybrid MHBMO-GRG algorithm was first suggested by Niazkar and Afzali [28] and was successfully applied for solving some problems in the water engineering field $[21,22,28-30]$. This hybrid algorithm comprises search-based and deterministic optimization algorithms used in two consecutive steps.

In the first step, a zero-order optimization algorithm, called MHBMO algorithm, commences the optimization process after evaluating the controlling parameters of the algorithm. Technically, this algorithm is inspired by the mating process of honey bees. The basic steps of the MHBMO algorithm are: (1) starting mating flight where a queen (best solution) probabilistically selects drones to create broods, (2) making new broods (trial solutions), (3) searching locally for new broods (trial solutions) by workers, (4) improving workers' fitness, and (5) finding the queen for the next generation by comparing the queen with the best brood [37-39]. The details of this algorithm are comprehensively presented in the literature $[40,41]$ for interested readers. In this hybrid method, the MHBMO algorithm precedes the optimization process for several numbers of iterations and results of the last iteration will be used as initial guesses for the next step.

In the second step, the problem is put in Excel spreadsheet. Then, the GRG algorithm, a first-order optimization technique, is utilized to continue the optimization process. This algorithm is one of the features embedded in Excel [42-44]. Although the MHBMO algorithm requires evaluation of five controlling algorithm parameters, GRG algorithm needs a set of initial guesses which are the results obtained in the last iteration of the first step in this hybrid method. The final optimum results obtained from the GRG algorithm highly depend on initial guesses. Therefore, the possibility of achieving a local optimum and initial guess requirement are the notable shortcomings of the MHBMO and GRG algorithms, respectively. However, the MHBMO-GRG hybrid method overcomes these drawbacks. It should be mentioned that according to the successful experience of applying this hybrid method to solve several problems [21,22,28-30], the new hybrid method not only enhances the applicability of the MHBMO algorithm in finding global optimum values, but adequately provides a set of initial guesses for the GRG algorithm.

\section{Application and results}

\subsection{Train and test data}

First of all, the considered database was randomly divided into two categories, namely training and testing datasets [21]. Since a generic equation is sought for bridge backwater, both experimental and field data are treated the same in this data-splitting process as those conducted in the relevant studies $[3,4,10]$. As mentioned earlier, the utilized database has 202 and 66 laboratory and field data sets, respectively. Of the total 268 data, $80 \%$ (161 experimental and 50 field data) were taken into account to calibrate the coefficients of the new formula, while the rest (41 experimental and 16 field data) were kept for comparison purpose. The maximum, minimum, and average values for the involved parameters and $d h / D_{3}$ for the total, training, and test datasets are presented in Table 1 , according to which, for all the parameters, the maximum of the training dataset is larger than the maximum of the test dataset and the minimum of the training dataset is lower than the minimum of the test dataset. In other words, the range of the training data is wider than that of the testing data which is indicative of a reasonable and adequate data division. Furthermore, according 
to Table 1, the new proposed model is applicable to downstream Froude number varying from 0.0075 to 1.8089 .

\subsection{Proposed models}

In this study, two artificial techniques, i.e., ANN and GP, and two optimization algorithms, i.e., GA and MHBMO-GRG, were calibrated through the training dataset. To be more specific, the unknown coefficients of the explicit proposed model (Eq. (5)) were optimized based on the training dataset using GA and MHBMOGRG. ANN and GP estimate bridge backwater without using the proposed model. In this regard, the same objective function was used in the training process for all these models. It is defined as minimizing the Root Mean Square Error (RMSE) between the computed and observed afflux to downstream depth $\left(d h / D_{3}\right)$ ratios. The sole constraint of this optimization process prevents bridge backwater from gaining a negative value. The objective function and the sole constraint are shown in Eqs. (6) and (7), respectively:

Minimize RMSE =

$$
\sqrt{\frac{\sum_{\mathrm{i}=1}^{\mathrm{N}}\left[\left(\frac{d h}{D_{3}}\right)_{i, \text { observed }}-\left(\frac{d h}{D_{3}}\right)_{i, \text { calculated }}\right]^{2}}{\mathrm{~N}}},
$$

Subjected to $\frac{d h}{D_{3}}>0$,

where $\left(\frac{d h}{D_{3}}\right)_{i, \text { observed }}$ and $\left(\frac{d h}{D_{3}}\right)_{i, c a l c u l a t e d}$ are the observed and calculated ratios of backwater to downstream water depth for the $i$ th data point and $N$ denotes the total number of the training dataset.

Since each data point was randomly allocated to either training or testing dataset, the two artificial models (ANN and GP) were trained for the training data and afterwards applied to estimate the testing data. However, the two utilized optimization algorithms (GA and MHBMO-GRG algorithm) were applied to the training dataset to find the optimum values of $p_{i}$ coefficients. In this regard, the controlling parameters in the MHBMO algorithm and GA were considered as the ones used in studies of Niazkar and Afzali [21] and Niazkar et al. [22], respectively. As a result, the new explicit equations proposed for bridge backwater estimation using GA and MHBMOGRG algorithm are introduced in Eqs. (8) and (9), respectively. According to Eq. (8), the parameter $J_{3}$ has two different impacts on bridge backwater. To be more specific, bridge backwater increases with a decrease in $J_{3}$ for $F_{3}<0.2$ and reduces with a decrease in $J_{3}$ for $F_{3} \geq 0.2$. Therefore, $J_{3}$ can have positive or negative influence on bridge backwater depending on the value of Froude number at the downstream. Additionally, the higher either $J_{1}$ or $F_{3}$ becomes, the

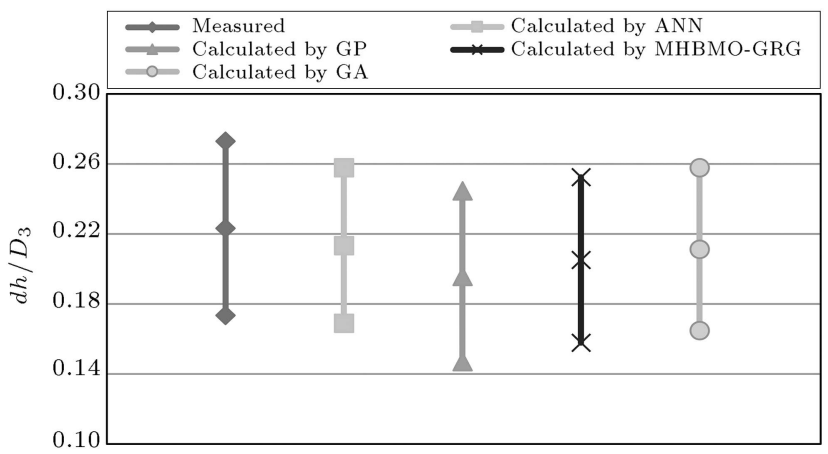

Figure 3. Confidence limits of different models for calculating bridge backwater for test data.

greater the bridge afflux will be. Eq. (9) obtained by GA appears to be applicable to most of the considered data, while implying that $d h / D_{3}$ increases upon an increase in each of $J_{1}, J_{3}$, or $F_{3}$.

$$
\begin{aligned}
& \frac{d h}{D_{3}}= \begin{cases}2.274 J_{1}^{5.328} J_{3}^{-0.899} F_{3}^{0.596} & \text { for } F_{3}<0.2 \\
5.243 J_{1}^{1.102} J_{3}^{0.822} F_{3}^{1.523} & \text { for } F_{3} \geq 0.2\end{cases} \\
& \frac{d h}{D_{3}}= \begin{cases}4.49 J_{1}^{1.39} J_{3}^{0.514} F_{3}^{1.421} & \text { for } F_{3}<1.179 \\
4.946 J_{1}^{1.519} J_{3}^{-0.267} F_{3}^{-3.242} & \text { for } F_{3} \geq 1.179\end{cases}
\end{aligned}
$$

The confidence limits of GP, ANN, Eq. (8), and Eq. (9) computed for the measured and calculated $d h / D_{3}$ values are given in Figure 3. In Figure 3, the ranges of bridge backwater values calculated by each model are compared for the testing data. As shown, the range of $d h / D_{3}$ values predicted by GP has the lowest minimum, average, and maximum values among all the considered methods, while the ranges achieved by ANN and Eq. (9) obtained by GA are very close to each other. Moreover, Figure 3 shows that the proposed explicit equations achieved by GA and MHBMO-GRG algorithm can be confidentially used for estimating bridge afflux for $d h / D_{3}$ placed within [0.165, 0.258] and $[0.158,0.252]$, respectively.

\subsection{Performance evaluation criteria}

In order to compare the performances of different models for better afflux estimation, five performance evaluation criteria are adopted from the literature $[3,10,45-47]$. These criteria include (1) Mean Square Error (MSE), (2) Mean Absolute Error (MAE), (3) Mean Absolute Relative Error (MARE), (4) Average of Individual Ratios (AIR), and (5) coefficient of determination $\left(R^{2}\right)$. These criteria are respectively introduced in Eqs. (10) to (14):

$$
\mathrm{MSE}=\frac{1}{N} \sum_{i=1}^{\mathrm{N}}\left[\left(\frac{d h}{D_{3}}\right)_{i, \text { observed }}-\left(\frac{d h}{D_{3}}\right)_{i, \text { calculated }}\right]_{(10)}^{2}
$$


Table 2. Comparison of the performance of different models for the train data.

\begin{tabular}{|c|c|c|c|c|c|}
\hline Methods & MSE & MAE & MARE & AIR & $R^{2}$ \\
\hline \multicolumn{6}{|c|}{ (a) Explicit equations } \\
\hline Biery and Delleur [2] & 0.0806 & 0.103 & 56.6 & 3.143 & 0.559 \\
\hline MLR [3] & 0.0498 & 0.1505 & 183 & 0.742 & 0.587 \\
\hline MLNR [3] & 0.0806 & 0.1144 & 63 & 1.235 & 0.494 \\
\hline MHBMO-GRG (this study) & 0.0358 & 0.0778 & 53.2 & 3.377 & 0.717 \\
\hline GA (this study) & 0.0131 & 0.0724 & 63.4 & 1.507 & 0.876 \\
\hline \multicolumn{6}{|c|}{ (b) Artificial intelligence models } \\
\hline GP (this study) & 0.0049 & 0.0346 & 31 & 2.079 & 0.957 \\
\hline ANN & 0.0083 & 0.0427 & 52.3 & 1.019 & 0.922 \\
\hline
\end{tabular}

$$
\begin{aligned}
& \text { MAE }=\frac{1}{N} \sum_{i=1}^{N}\left|\left(\frac{d h}{D_{3}}\right)_{i, \text { observed }}-\left(\frac{d h}{D_{3}}\right)_{i, \text { calculated }}\right| \\
& \text { MARE }= \frac{1}{N} \sum_{i=1}^{N}\left|\frac{\left(\frac{d h}{D_{3}}\right)_{i, \text { observed }}-\left(\frac{d h}{D_{3}}\right)_{i, \text { calculated }} \mid}{\left(\frac{d h}{D_{3}}\right)_{i, \text { observed }}}\right| \\
& \times 100, \\
& \text { AIR }= \frac{1}{N} \sum_{i=1}^{N}\left[\frac{\left(\frac{d h}{D_{3}}\right)_{i, \text { observed }}}{\left(\frac{d h}{D_{3}}\right)_{i, \text { calculated }}}\right]
\end{aligned}
$$

Eq. (14) is shown in Box I.

\subsection{Comparison results}

Through these five evaluation criteria, the performance of different models applied to afflux estimation was compared, as shown in Tables 2 and 3, for the training and testing data sets, respectively. As shown in Table 2, GP achieved the lowest (best) values for MSE, MAE, and MARE and the largest (best) values for $R^{2}$ in comparison with other ones for the training data, while ANN obtained the best value for AIR criterion in Table 2. Among the explicit equations listed in Table 2, Eq. (9) determined by GA outperformed others in terms of MSE, MAE, and $R^{2}$, while Eq. (8) developed by the MHBMO-GRG algorithm achieved the best MARE for the training data. According to Table 3, ANN obtained the lowest (best) values for MSE, MAE and the largest (best) values for $R^{2}$, while GP scored the best MARE for the testing data among all the considered models. Furthermore, the new explicit equation calibrated using GA outperformed other ones in Table 3 with respect to MSE, MAE, MARE, and $R^{2}$ criteria. The results shown in Tables 2 and 3 clearly demonstrate that the application of available empirical equation, e.g., Biery and Delleur [2], may yield significant errors in the bridge backwater estimation. However, the new explicit equations may serve as adequate alternatives as they considerably improve afflux estimation in four out of the five considered criteria.

Figures 4 and 5 depict measured versus predicted $d h / D_{3}$ values calculated by GP, ANN, Eqs. (8), and (9) for training and testing data sets, respectively. As shown, $R^{2}$ values for these models can also be compared using these figures. Based on Figures 4 and 5, GP and ANN achieved the best $R^{2}$ values for the training and testing data sets, respectively. Moreover, Figure 6 compares the relative errors calculated by ANN, GP, GA, and MHBMO-GRG algorithms for the whole data. As shown, all these four models would make relative errors close to zero for most of data because most of the points depicted in Figure 6 are placed near the hor-

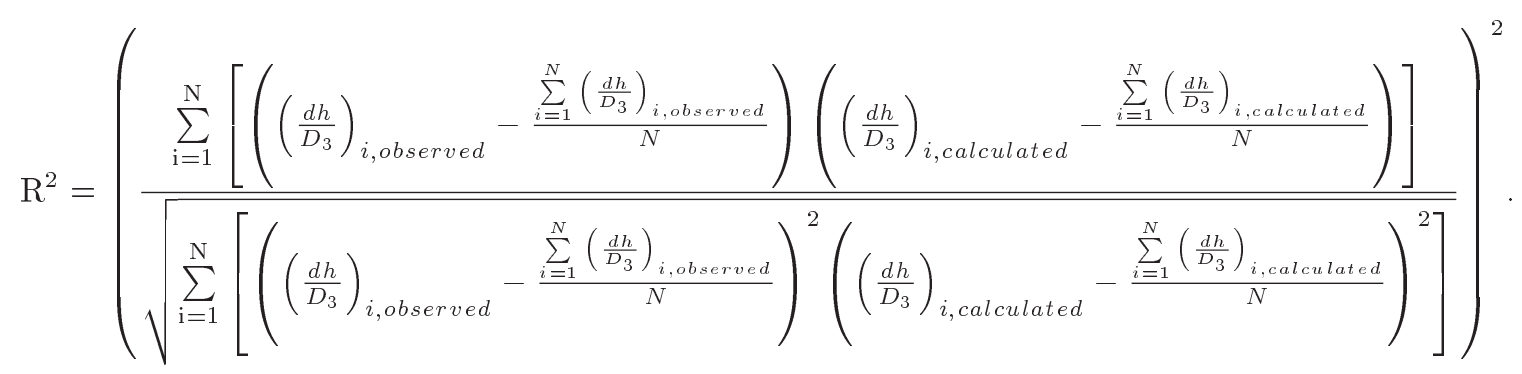


Table 3. Comparison of the performance of different models for the test data.

\begin{tabular}{lccccc}
\hline Methods & MSE & MAE & MARE & AIR & $\boldsymbol{R}^{\mathbf{2}}$ \\
\hline Biery and Delleur [2] & (a) Explicit equations & & & \\
MLR [3] & 0.0140 & 0.0800 & 39.9 & 3.296 & 0.685 \\
MLNR [3] & 0.0177 & 0.1156 & 123 & 0.689 & 0.610 \\
MHBMO-GRG (this study) & 0.0083 & 0.0637 & 45.5 & 4.582 & 0.782 \\
GA (this study) & 0.0077 & 0.0621 & 41.1 & 1.456 & 0.792 \\
\hline \multicolumn{7}{c}{ (b) Artificial intelligence } & models & & \\
\hline GP (this study) & 0.0066 & 0.0504 & 30.6 & 2.99 & 0.842 \\
ANN & 0.0043 & 0.0464 & 32.9 & 1.034 & 0.887 \\
\hline
\end{tabular}

izontal line. According to Figure 6, ANN achieves two considerable negative relative error values; however, other models yield several large positive relative errors. This indicates that ANN significantly underestimates two data points, while others overestimate bridge backwater for several data points in the considered data base. Finally, the maximum and minimum relative errors are achieved by GA and ANN in Figure 6, respectively.

In order to determine the percentages of bridge afflux calculated within different error ranges and percentage deviations, the maximum, minimum, and average values of percentage deviations between the 45-degree line and measured and calculated bridge backwaters are computed using all seven models and listed in Table 4. As shown, the average percentage deviation, i.e.:

$$
\left[\frac{\left(\frac{d h}{D_{3}}\right)_{i, \text { calculated }}-\left(\frac{d h}{D_{3}}\right)_{i, \text { observed }}}{\left(\frac{d h}{D_{3}}\right)_{i, \text { observed }}}\right] \times 100,
$$

for the testing data using Biery and Delleur's [2] equation is $-20.57 \%$, while the corresponding value calculated by the MHBMO-GRG algorithm is $-3.81 \%$. Furthermore, the latter one, which has the lowest average percentage deviation in Table 4, predicted more than $7 \%$ and $40 \%$ of the corresponding bridge backwater values within $\pm 5 \%$ and $\pm 25 \%$ error ranges,
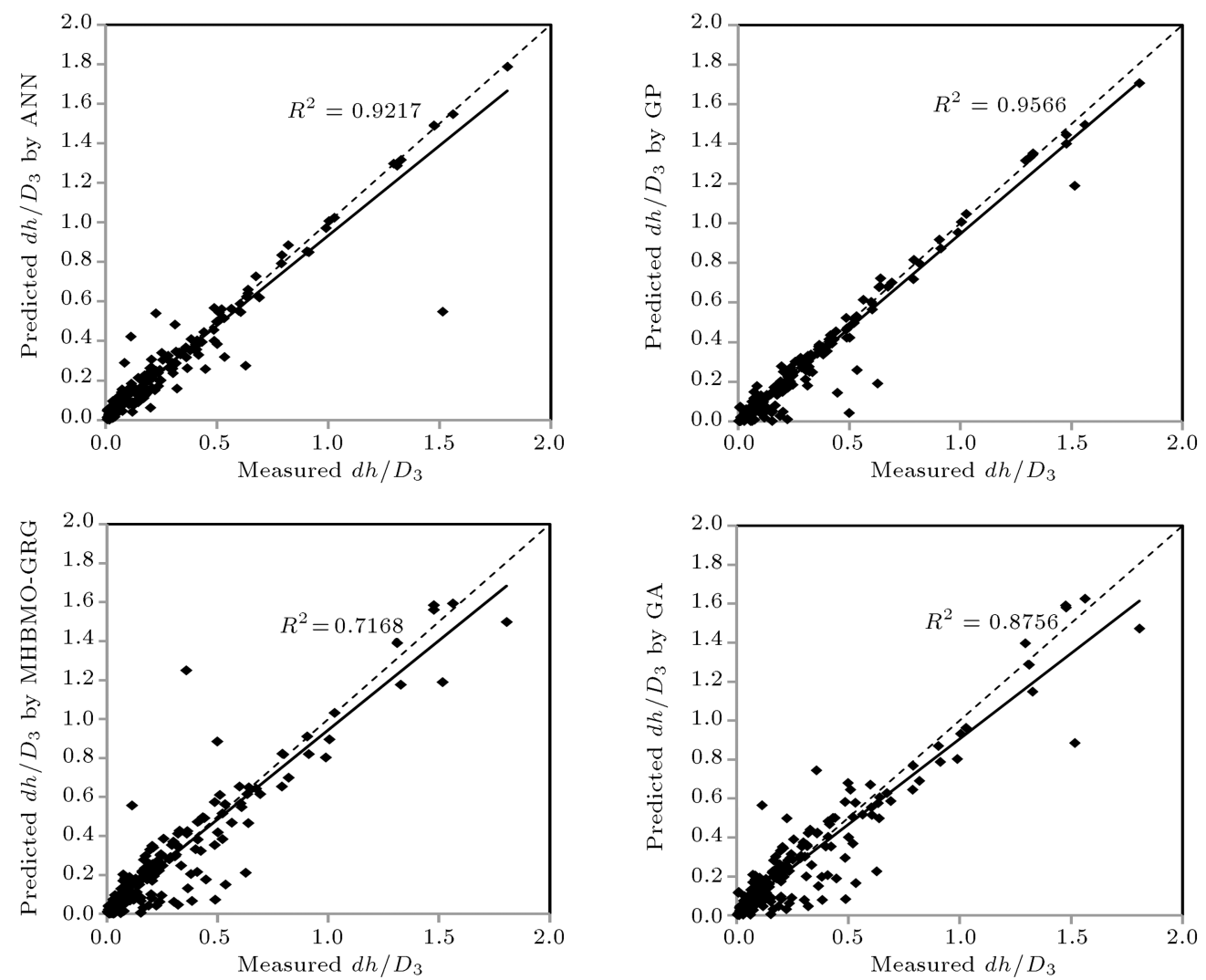

Figure 4. Comparison of $R^{2}$ values calculated by different models for training data. 

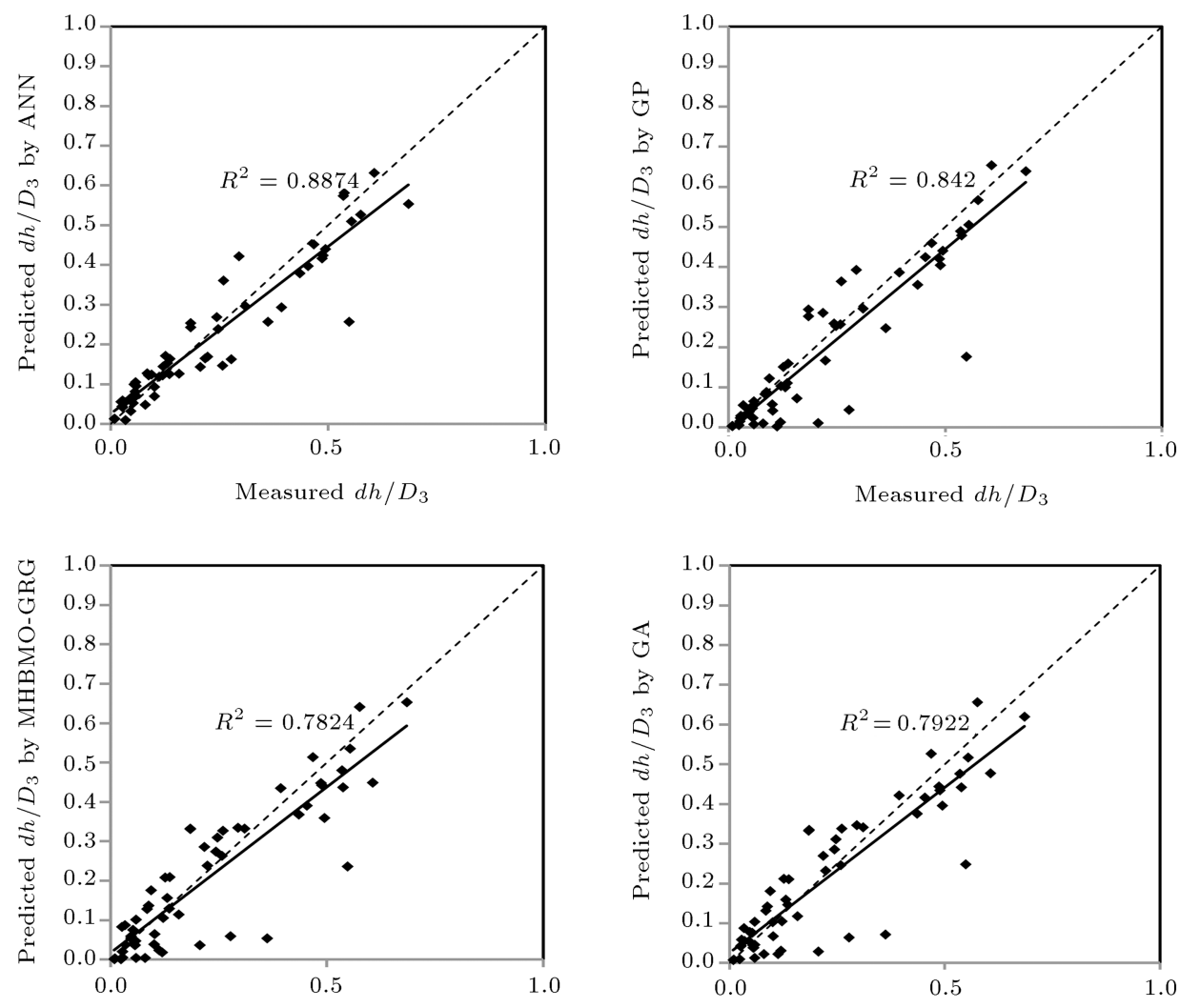

Measured $d h / D_{3}$

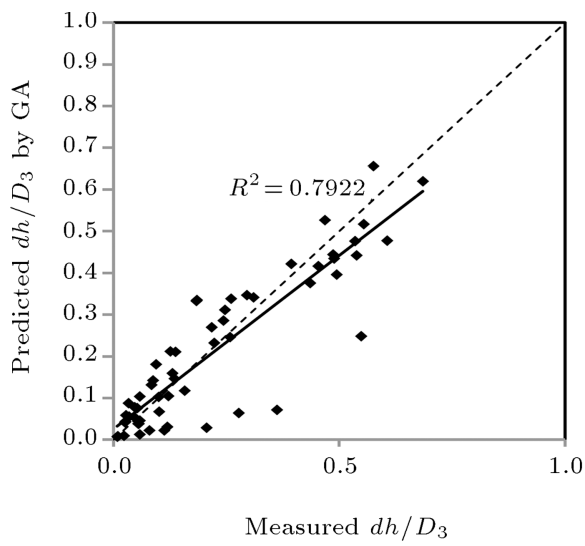

Figure 5. Comparison of $R^{2}$ values calculated by different models for testing data.
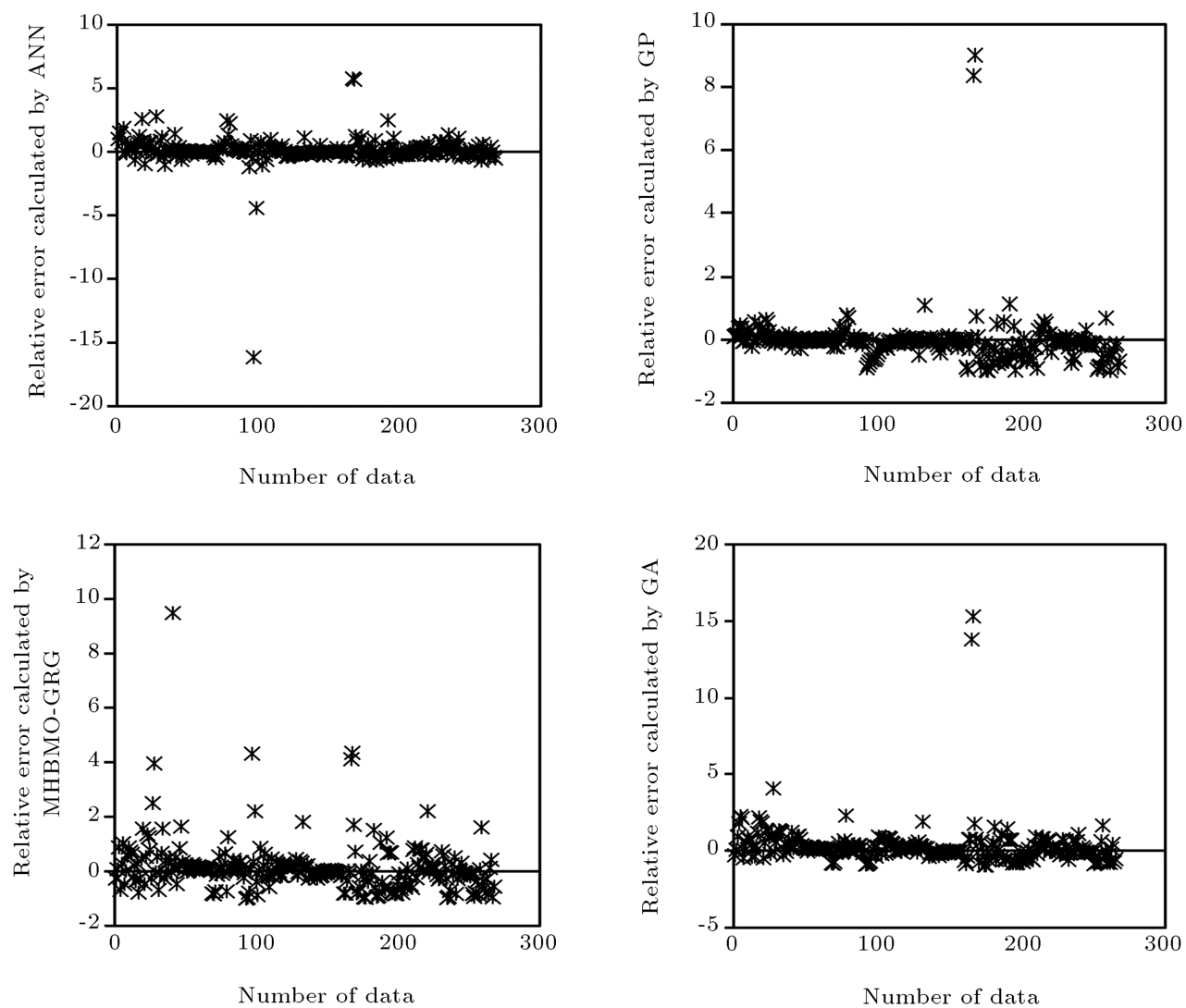

Figure 6. Comparison of relative errors calculated by different models. 
Table 4. Comparison of percentages of error ranges and deviation calculated by different models for the test data.

\begin{tabular}{|c|c|c|c|c|c|c|c|c|}
\hline \multirow[b]{2}{*}{ Methods } & \multicolumn{5}{|c|}{$\begin{array}{l}\text { Percentages of calculated } d h / D_{3} \\
\text { in error ranges }\end{array}$} & \multicolumn{3}{|c|}{ Percentage deviation } \\
\hline & $\begin{array}{c} \pm 5 \% \\
\text { errors }\end{array}$ & $\begin{array}{l} \pm 10 \% \\
\text { errors }\end{array}$ & $\begin{array}{l} \pm 15 \% \\
\text { errors }\end{array}$ & $\begin{array}{l} \pm 20 \% \\
\text { errors }\end{array}$ & $\begin{array}{l} \pm 25 \% \\
\text { errors }\end{array}$ & $\operatorname{Max}$ & Min & Average \\
\hline \multicolumn{9}{|c|}{ (a) Explicit equations } \\
\hline Biery and Delleur [2] & 3 & 6 & 9 & 14 & 20 & 66.07 & -97.99 & -20.57 \\
\hline MLR [3] & 4 & 5 & 6 & 7 & 10 & 580.62 & -44.45 & 112.55 \\
\hline MLNR [3] & 3 & 5 & 9 & 15 & 21 & 142.90 & -84.57 & 0.28 \\
\hline MHBMO-GRG (this study) & 4 & 10 & 18 & 21 & 23 & 219.76 & -99.15 & -3.81 \\
\hline GA (this study) & 3 & 10 & 17 & 23 & 27 & 163.15 & -86.28 & 6.34 \\
\hline \multicolumn{9}{|c|}{ (b) Artificial intelligence models } \\
\hline GP (this study) & 9 & 17 & 25 & 31 & 33 & 69.52 & -98.21 & -17.08 \\
\hline ANN & 6 & 13 & 19 & 24 & 27 & 139.09 & -70.39 & 12.26 \\
\hline
\end{tabular}

respectively. However, Biery and Delleur's [2] formula achieved more than $5 \%$ and $35 \%$ of afflux testing data within $\pm 5 \%$ and $\pm 25 \%$ error ranges, respectively. This comparison also demonstrates that the suggested equations are capable of estimating bridge backwater values within better accuracy range than the available explicit ones. Furthermore, GP predicts bridge backwater values with the highest percentage within $\pm 5 \%$ and $\pm 25 \%$ error ranges for the testing data.

The explicit equations, like those developed by GA or the hybrid MHBMO-GRG algorithm in this study, do not require calibration and may be applicable to whatever situation that fits within the ranges of the dataset used for its development. Therefore, these empirical equations may be implemented using river engineering software to estimate bridge backwater depth. Furthermore, AI models, like ANN and GP, give a better estimation of bride backwater depth than all the explicit equations while they need a training process using a reliable dataset. However, once they were trained, they could be exploited for scenarios whose parameters are within the corresponding ranges of the training data. Therefore, the explicit equations and AI models have a valid range of applications, which may be considered as their limitation or disadvantages. Obviously, the wider the range of the training data, the more situations they can be used for estimation of bridge afflux. As a result, the applied model not only performs much better than the available explicit formulas for estimating bridge afflux values but also can be alternatively used in practice within its applicable range of validity.

\section{Conclusions}

Bridge backwater has been always an inevitable challenge for the safety and management of bridge and channels sides particularly during flood events. Con- sequently, the necessity of performing more accurate estimation of bridge afflux has provided an active field of research area in the hydraulic structure engineering field. According to the literature, various models have been recommended based on experimental and field data sets for this purpose. Additionally, the literature review reveals lack of availability of accurate explicit equations developed by applying powerful optimization algorithms like Genetic Algorithm (GA). Furthermore, even though several AI models have been already applied to predicting afflux for arched bridges, genetic programming was utilized for this purpose for the first time in this study to the authors' knowledge. In this paper, seven models including Artificial Neural Network (ANN), Genetic Programming (GP), Genetic Algorithm (GA), and hybrid MHBMO-GRG algorithm and three explicit equations available in the literature were compared for backwater prediction. The two optimization algorithms were used to develop two new accuracy-improved explicit equations. Comparing the performance of these seven models using five evaluation criteria obviously indicates that the new explicit equations outperform the ones available in the literature while GP and ANN perform as the two best models among all the considered ones. To be more specific, GP achieved $R^{2}$ value equal to 0.957 and 0.842 for the training and testing data, respectively, while ANN obtained 0.922 and 0.887 values for the corresponding criterion. Because of this precision improvement, the applied models may be confidentially altered with the current explicit ones available in the literature for backwater estimation within its range of applicability.

\section{References}

1. Hunt, J., Brunner, G.W., and Larock, B.E. "Flow transitions in bridge backwater analysis", J. Hydraul. Eng., 125(9), pp. 981-983 (1999). 
2. Biery, P. and Delleur, J. "Hydraulics of single span arch bridge construction", J. Hydraul. Eng., 88(2), pp. 75-108 (1962).

3. Mamak, M., Seckin, G., Cobaner, M., et al. "Bridge afflux analysis through arched bridge constrictions using artificial intelligence methods", Civ. Eng. Environ. Syst., 26(3), pp. 279-293 (2009).

4. Pinar, E., Paydas, K., Seckin, G., et al. "Artificial neural network approaches for prediction of backwater through arched bridge constrictions", Adv. Eng. Softw., 41(4), pp. 627-635 (2010).

5. Biglari, B. and Sturm, T.W. "Numerical modeling of flow around bridge abutments in compound channel", J. Hydraul. Eng., 124(2), pp. 156-164 (1998).

6. Seckin, G., Haktanir, T., and Knight, D. "A simple method for estimating flood flow around bridges", $P$. I. Civil Eng-Wat. M., 160, pp. 195-202 (2007).

7. Seckin, G., Yurtal, R., and Haktanir, T. "Contraction and expansion losses through bridge constrictions", $J$. Hydraul. Eng., 124(5), pp. 546-549 (1998).

8. Seckin, G. and Atabay, S. "Experimental backwater analysis around bridge waterways", Can. J. Civil Eng., 32(6), pp. 1015-1029 (2005).

9. Seckin, G., Akoz, M.S., Cobaner, M., et al. "Application of ANN techniques for estimating backwater through bridge constrictions in Mississippi river basin", Adv. Eng. Softw., 40(10), pp. 1039-1046 (2009).

10. Pinar, E., Seckin, G., Sahin, B., et al. "ANN approaches for the prediction of bridge backwater using both field and experimental data", Int. J. of River Basin Manag., 9(1), pp. 53-62 (2011).

11. Seckin, G., Cobaner. M., Ozmen-Cagatay, H., et al. "Bridge afflux estimation using artificial intelligence systems", P. I. Civil Eng-Wat. M., 164, pp. 283-293 (2011).

12. Schneider, V. and Arcement, G. "Guide for selecting manning's roughness coefficients for natural channels and flood plains", Available from the US Geological Survey, Books and Open-File Reports Section, Box 25425, Federal Center, Denver, CO 80225-0425. WaterSupply Paper 2339, 1989. 38 p, 22 g, 4 tab, 23 ref (1989).

13. Hydrologic Engineering Center, HEC-2 Water Surface Profiles User's Manual, Hydrologic Eng. Ctr., Davis, CA: US Army Corps of Engineers (1991).

14. Hydrologic Engineering Center, HEC-RAS River Analysis System, Hydrologic Eng. Ctr., Davis, CA: US Army Corps of Engineers, version 3.1, beta Edn. (2002).

15. Hydrologic Engineering Center, HEC-RAS River Analysis System, Hydrologic Eng. Ctr., Davis, CA: US Army Corps of Engineers, version 1.0, Edn. (1995)

16. Sherman, J. "User's manual for WSPRO. A computer model for water surface profile computation", US Geological Survey, Reston, Va. Report No. FHWA-IP89-027 (1990).
17. Yarnell, D.L., Bridge Piers as Channel Obstructions, (No. 442), US Dept. of Agriculture (1934).

18. Brown, P. "Afflux at arch bridges", Tech. Rep. Report SR 182, HR Wallingford (1988).

19. Bradley, J.N., Hydraulics of Bridge Waterways, 2nd Edn., Series No. 1, Washington DC: Office of Engineering, US Department of Transportation, Federal Highway Administration (1978).

20. Hallcrow, S.W. and Wallingford, H.R., ISIS Flow User Manual, Version 2.1., Sir William Halcrow \& Partners and HR Wallingford Ltd., Wallingford, UK (2002).

21. Niazkar, M. and Afzali, S.H. "Developing a new accuracy-improved model for estimating scour depth around piers using a hybrid method", IJST-T Civ. Eng., 43(2), pp. 179-189 (2018).

22. Niazkar, M., Rakhshandehroo, G., and Afzali, S.H. "Deriving explicit equations for optimum design of a circular channel incorporating a variable roughness", IJST-T Civ. Eng., 42(2), pp. 133-142 (2018). DOI 10.1007/s40996-017-0091-y

23. Niazkar, M. "Revisiting the estimation of colebrook friction factor: A comparison between artificial intelligence models and C-W based explicit equations", KSCE J. Civ. Eng., 23(10), pp. 4311-4326 (2019).

24. Niazkar, M., Talebbeydokhti, N., and Afzali, S.H. "Relationship between Hazen-William coefficient and Colebrook-White friction factor: Application in water network analysis", European Water, 58, pp. 513-520 (2017).

25. Niazkar, M. and Talebbeydokhti, N. "Comparison of explicit relations for calculating Colebrook friction factor in pipe network analysis using h-based methods", Iranian Journal of Science and Technology, Transactions of Civil Engineering, 44(1), pp. 231-249 (2020). DOI: $10.1007 / \mathrm{s} 40996-019-00343-2$

26. Sivapragasam, C., Maheswaran, R., and Venkatesh, V. "Genetic programming approach for flood routing in natural channels", Hydrol. Process, 22(5), pp. 623-628 (2008).

27. Niazkar, M., Talebbeydokhti, N., and Afzali, S.H. "Novel grain and form roughness estimator scheme incorporating artificial intelligence models", Water Resour. Manag., 33(2), pp. 757-773 (2019).

28. Niazkar, M. and Afzali, S.H. "Application of new hybrid optimization technique for parameter estimation of new improved version of Muskingum model", Water Resour. Manag., 30(13), pp. 4713-4730 (2016).

29. Niazkar, M. and Afzali, S.H. "Parameter estimation of an improved nonlinear Muskingum model using a new hybrid method", Hydrol. Res., 48(4), pp. 1253-1267 (2017).

30. Niazkar, M. and Afzali, S.H. "Application of new hybrid method in developing a new semicircular-weir discharge model", Alexandria Eng. J., 57(3), pp. 17411747 (2017). 
31. Cobaner, M., Seckin, G., and Kisi, O. "Initial assessment of bridge backwater using an artificial neural network approach", Can. J. Civil Eng., 35(5), pp. 500510 (2008).

32. Govindaraju, R.S. "Artificial neural networks in hydrology. I: Preliminary concepts", Journal of Hydrologic Engineering, 5(2), pp. 115-123 (2000).

33. Samet, K., Hoseini, K., Karami, H., et al. "Comparison between soft computing methods for prediction of sediment load in rivers: Maku dam case study", IJSTT Civ. Eng., 43(1), pp. 93-103 (2019).

34. Vaghefi, M., Mahmoodi, K., and Akbari, M. "Detection of outlier in $3 \mathrm{D}$ flow velocity collection in an openchannel bend using various data mining techniques", IJST-T Civ. Eng., 43(2), pp. 197-214 (2019).

35. Koza, J.R., Bennett, F.H., and Stiffelman, O. "Genetic programming as a Darwinian invention machine", In: European Conference on Genetic Programming, pp. 93-108. Springer (1999).

36. Francone, F.D. "Discipulus owner's manual", $M a-$ chine Learning Technologies, Inc., Littleton, Colorado (1998).

37. Afzali, S.H., Darabi, A., and Niazkar, M. "Steel frame optimal design using MHBMO algorithm", Int. J. Steel Struct., 16(2), pp. 455-465 (2016).

38. Niazkar, M. and Afzali, S.H. "New nonlinear variableparameter Muskingum models", KSCE J. Civ. Eng., 21(7), pp. 2958-2967 (2017).

39. Niazkar, M. and Afzali, S.H. "Closure to assessment of modified honey bee mating optimization for parameter estimation of nonlinear Muskingum models", $J$. Hydrol. Eng., 23(4), 07018003 (2018).

40. Niazkar, M. and Afzali, S.H. "Assessment of modified honey bee mating optimization for parameter estimation of nonlinear Muskingum models", J. Hydrol. Eng., 20(4), 04014055 (2015).

41. Niazkar, M. and Afzali, S.H. "Optimum design of lined channel sections", Water Resour. Manag., 29(6), pp. 1921-1932 (2015).

42. Niazkar, M. and Afzali, S.H. "Streamline performance of Excel in stepwise implementation of numerical solutions", Comput. Appl. Eng. Educ., 24(4), pp. 555566 (2016).

43. Niazkar, M. and Afzali, S.H. "Analysis of water distribution networks using MATLAB and Excel spreadsheet: h-based methods", Comput. Appl. Eng. Educ., 25(1), pp. 129-141 (2017).

44. Niazkar, M. and Afzali, S.H. "Analysis of water distribution networks using MATLAB and Excel spreadsheet: Q-based methods", Comput. Appl. Eng. Educ., 25(2), pp. 277-289 (2017).

45. Niazkar, M., Talebbeydokhti, N., and Afzali, S.H. "Development of a new flow-dependent scheme for calculating grain and form roughness coefficients", KSCE J. Civ. Eng., 23(5), pp. 2108-2116 (2019).
46. Motaman, F., Rakhshandehroo, G.R., Hashemi, M.R., et al. "Application of RBF-DQ method to timedependent analysis of unsaturated seepage", Transport in Porous Media, 125(3), pp. 543-564 (2018).

47. Niazkar, M., Talebbeydokhti, N., and Afzali, S.H. "One dimensional hydraulic flow routing incorporating a variable grain roughness coefficient", Water Resour. Manag., 33(13), pp. 4599-4620 (2019).

\section{Biographies}

Majid Niazkar received his BS degree in Civil Engineering (2012), MS degree in Hydraulic Structures (2014), and PhD degree in Water Resources all from the Department of Civil and Environmental Engineering, Shiraz University, Shiraz, Iran. He is currently a research assistant at the Department of Civil and Environmental Engineering, Shiraz University, Shiraz, Iran. He has published 18 ISI papers, one ISC paper, and 30 papers in international and national conferences. His research interests include hydrology (specifically, flood modeling and routing), hydraulic engineering (specifically, open-channel hydraulics and channel design), water distribution networks, optimization, numerical modeling, water resources management, critical infrastructure protection, groundwater, soft-computing techniques (ANN and genetic programming) for hydrologic modeling, river engineering and sediment transport, bed roughness prediction, and assessing the impacts of climate change. He also has reviewed some papers for several ISI journals including Water Resources Management, Urban Water Journal, Arabian Journal for Science and Engineering, and Computer Applications in Engineering Education.

Nasser Talebbeydokhti received his $\mathrm{PhD}$ degree in Water Resources and Hydraulic Engineering (1984) from the Department of Civil and Environmental Engineering, Oregon State University, Corvallis USA. He is a Professor of Civil and Environmental Engineering with 40 years of teaching, research, and consulting activities that cover broad areas of water resources and environmental engineering. He is currently the Editorin-Chief of Iranian Journal of Science \& Technology, Transactions of Civil Engineering. $\mathrm{He}$ is a member of Academy of Sciences of Iran. He also received a distinguished award for the best teaching professor in Iran in 2018. His research interests include environmental engineering; Strategic environmental assessment; spatial planning; hydrology; river hydraulics, watershed engineering, sediment transport and channel morphology; hydraulic structures; hydropower; environmental impact assessment and mitigation; HSE; water resources planning; water quality management and monitoring; integrated watershed management; coastal and estuarine sediment; and river resource 
planning and management. He is the author of more than 312 papers in national and international journals and conference proceedings. Also, $19 \mathrm{PhD}$ theses have been defended under his supervision and he served as an advisor in more than $30 \mathrm{PhD}$ theses.

Seied Hosein Afzali received his BS degree from the Department of Civil and Environmental Engineering, Shiraz University, Shiraz, Iran in 1986 and the MSc degree from the Department of Civil Engineering, Amirkabir University of Technology, Tehran, Iran, in 1988.
His $\mathrm{PhD}$ is in Hydraulic Structures (2008) from the Department of Civil and Environmental Engineering, Shiraz University, Shiraz, Iran. Dr. Afzali is currently an Associate Professor of Civil Engineering at Shiraz University, Shiraz, Iran. His research interests include groundwater, hydraulic structures, river engineering, optimization problems, and fluid mechanics. He is the author of more than 77 papers in national and international journals and conference proceedings. He is also the first author of a textbook about open channel hydraulics translated in Persian. 